\title{
On the Sensitivity of Numerical Weather Prediction to Remotely Sensed Marine Surface Wind Data: A Simulation Study
}

\author{
Mark A. Cane,' Vincent J. Cardone, ${ }^{2}$ Milton Halem, ${ }^{3}$ and Isidore Halberstam ${ }^{4}$
}

\begin{abstract}
A series of observing system simulation experiments has been performed to assess the potential impact of marine surface wind data on numerical weather prediction. Care was taken to duplicate the spatial coverage and error characteristics of conventional surface, radiosonde, ship, and aircraft reports. These observations, suitably degraded to account for instrument and sampling errors, were used in a conventional analysis-forecast cycle. A series of five 72-hour forecasts were then made by using the analyzed fields as initial conditions. The forecast error growth was found to be similar to that in operational numerical forecasts. Further experiments simulated the time-continuous assimilation of remotely sensed marine surface wind or temperature sounding data in addition to the conventional data. The wind data were fabricated directly for model grid points intercepted by a Seasat-1 scatterometer (SASS) swath and were placed in the lowest active level ( $945 \mathrm{mbar}$ ) of the model. The temperature sounding experiment assimilated error-free data fabricated along actual Nimbus orbits. Forecasts were made from the resulting analysis fields, and the impact of the simulated satellite data was assessed by comparing these forecast errors with those of the control forecasts. When error-free winds were assimilated by using a localized successive correction method (SCM), the impacts in extratropical regions proved to be substantial, especially in lower tropospheric quantities such as surface pressure. In contrast, a less sophisticated assimilation method resulted in negligible impact. The assimilation of error-free sounder data (again by the SCM) gave impacts comparable to the wind data, suggesting that surface wind data alone may be as valuable as temperature soundings for numerical weather prediction. The effects of nominal SASS errors ( $\pm 2 \mathrm{~m} / \mathrm{s}$ in magnitude, $\pm 20^{\circ}$ in direction) on the impacts derived from wind data were found to be small.
\end{abstract}

\section{INTRODUCTION}

The objective of the study reported here is to assess the potential impact on numerical weather prediction (NWP) of remotely sensed surface wind data. The motivation for this was the promise of obtaining such data in quantity from the scatterometer on Seasat-1 and follow on satellites. At the time the study was initiated (and as of this writing) an adequate volume of real data was not available so the methodology employed here is that of observing system simulation experiments. For comparison purposes a parallel experiment was conducted with simulated Nimbus temperature sounding data (for which there is experience with real data [e.g., Ghil et al., 1979]).

Since the advent of the Global Atmospheric Research Program (GARP), a large number of simulation studies have been conducted to assess the impact of proposed observing systems on numerical weather prediction [see, e.g., the review by $M c P h e r s o n, 1975]$. By and large these studies have proceeded by comparing a 'nature run' produced with a general circulation model (GCM) with a similar run where the initial conditions are altered by the addition of random errors. Such a procedure gives an unrealistic distribution of initial errors and leads to error growth curves in simulated forecasts unlike those found in actual forecasts. In particular, the errors show an initial decrease, as gravity waves act to smooth these random perturbations. Nitta et al. [1975] reported observing system simulation experiments (OSSE) that included more realistic initial error specifications.

In the present study, care has been taken to duplicate the

\footnotetext{
' Department of Meteorology, Massachusetts Institute of Technology, Cambridge, Massachusetts 02139.

2 Oceanwater, Inc., White Plains, New York 10601.

${ }^{3}$ Laboratory for Atmospheric Sciences, NASA/Goddard Space Flight Center, Greenbelt, Maryland 20771.

${ }^{4}$ Jet Propulsion Laboratory, Pasadena, California 91103.
}

Copyright (c) 1981 by the American Geophysical Union. actual distribution of information in the conventional observ ing system, thus shifting the emphasis from accuracy of the data to the data coverage. This is an important consideration in assessing satellite observing systems since experience with sounder data [Ghil et al., 1979] has shown that improvements in forecasts due to satellite-derived information is due less to a general error reduction than to the ability to fill data-sparse regions.

The study reported here concentrates on the evaluation of the observing system simulation experimental design and on the assessment of the potential of remotely sensed marine surface wind data. The concept of 'measuring' marine surface wind by using a radar scatterometer to measure the radar return signal from surface capillary waves has been proven on Skylab [Cardone et al., 1976]. The results of that experiment indicated that scatterometer-derived wind measurements are at least as accurate as conventional ship reports, including those from ocean station vessels.

A more advanced scatterometer (SASS) was flown on Seasat-1 [Grantham et al., 1977]. (Seasat-1 was launched on June 26, 1978, and stopped transmitting on October 9, 1978, after acquiring global data over a period of 99 days.) While fundamentally the scatterometer measures some property of the sea surface (e.g., capillary wave roughness, surface stress), it has been shown on the basis of numerous experiments that the measurement can be defined operationally as one of the surface layer wind speed and direction, referred to a stated anemometer level (usually $19.5 \mathrm{~m}$ ) and to neutral atmospheric stability [see, e.g., Jones et al., 1978]. The design goal for accuracy of SASS measurements is $\pm 2 \mathrm{~m} / \mathrm{s}$, or $10 \%$ of the speed, whichever is greater, for wind speed, and $\pm 20^{\circ}$ in wind direction. Preliminary evaluations of SASS [e.g., Jones et al., 1979] suggests that the design accuracies have been achieved.

Scatterometer-derived winds should be well suited to numerical weather prediction, since the winds represent spatial averages over typical grid boxes in NWP models, whereas conventional measurements of marine surface wind from buoys, weather ships, and transient ships are averaged over 


\section{DISCRETIZATION OF ATMOSPHERE INTO GRID ELEMENTS}

\section{LATITUDE-LONGITUDE GRID}

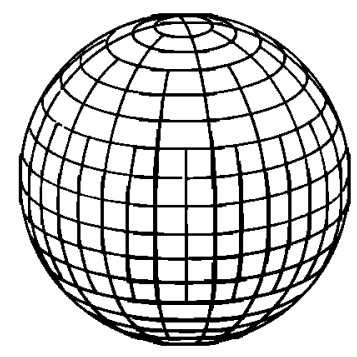

VERTICAL SIGMA LEVELS

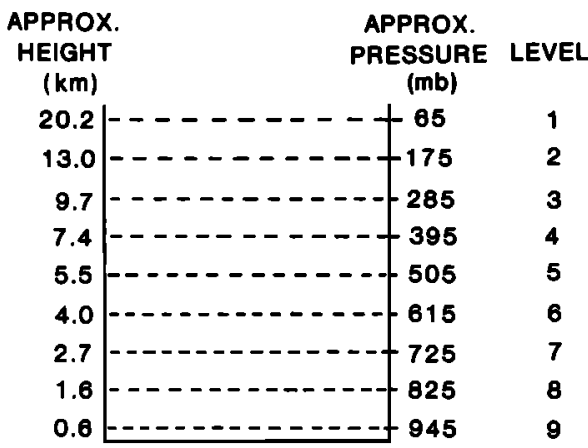

Fig. 1. Horizontal and vertical resolution of the GLAS GCM grid.

too short an interval to be so representative. Nevertheless, the data are novel, and it is not known presently how to exploit best such measurements and how much improvement in environmental forecasts can be expected.

The satellite simulation experiments reported here are idealized. In most of the simulations, the scatterometer data are assumed to be error free. The data are also assumed to be representative of the lowest active layer of the GCM, implying perfect knowledge of the planetary boundary layer. An idealized sounder simulation experiment was performed assuming perfectly retrieved temperatures. Finally, the experiments are idealized because of their 'identical twin' nature, which means that, in effect, the forecast model has perfect physics and sufficient resolution. This will be discussed further below.

\section{EXPERIMENTAL DESIGN}

The experiment requires four elements:

1. A nature run to provide a complete record of the state of the model atmosphere. This record is used both to fabricate 'observational' reports and to evaluate analyses and forecasts.

2. A control assimilation that is like an operational forecast-analysis cycle based on conventional observations, except that it makes use of fabricated data to produce the analyzed fields.

3. A satellite assimilation that differs from the control in including fabricated satellite data in the forecast-analysis cycle.

4. Forecasts produced from both control and satellite ini- tial conditions. Comparison of these forecasts provides an assessment of the impact of the satellite data.

Nature run. All time integrations were made with the Goddard Laboratory for Atmospheric Sciences (GLAS) GCM, essentially as described by Somerville et al. [1974], except that the present version employs the split grid [Halem and Russell, 1973] illustrated in Figure 1. Equatorward of $60^{\circ}$ the grid spacing is $4^{\circ}$ of latitude by $5^{\circ}$ of longitude. At $60^{\circ}$ the longitudinal spacing doubles and at $78^{\circ}$ it doubles again. A sigma coordinate system with nine levels is employed in the vertical; note that the lowest level, level 9 , is at approximately 945 mbar over the oceans. In the satellite assimilation experiments, wind data will be inserted at this level. Many of the statistics used to evaluate the experiment are based on the level 5 zonal wind (U5); over the oceans, level 5 is very nearly the 500-mbar level (Figure 1). The forecasting ability of this model has been documented in a number of places [Baumhefner and Downey, 1976; Druyan et al., 1975]; its skill was found to be comparable to other large forecasting models, such as the operational model at the National Meteorological Center (NMC).

The nature run is a month-long model integration starting from initial conditions for February 1, 1976, taken from the NMC analyses. The choice of initial conditions is somewhat arbitrary; a northern hemisphere winter month seemed a good choice because of the greater meteorological activity. This particular choice enables us to compare the simulation statistics with real data statistics derived from actual forecasts made with the GLAS GCM during the same period [Ghil et al., 1977]. Of course, it is necessary to base the experiment on a synthetic version of 'nature' rather than on reality because the goal is to study the effects of observational data that are not presently available. To be able to fabricate such data, all the basic model variables were saved for each grid point (3300 points) at each 10 -min time interval.

Control assimilation. The control assimilation resembles the forecast-analysis cycle employed by operational meteorological centers, though it is not our intention to duplicate the procedures of any given operational center. This would be difficult since such procedures recently have undergone rapid changes, primarily to accommodate satellite data. For example, NMC has begun to incorporate cloud tracked winds and has switched from a 12-hour to a 6-hour cycle. The control experiment was designed to serve as a baseline against which one or more types of remote sensing data can be evaluated. Thus we have chosen to restrict the control to conventional data by excluding remote sensing measurements, such as cloud-tracked winds. Winds from a scatterometer or an operation polar orbiter may be viewed as an alternative to lowlevel cloud-tracked winds since they provide greater accuracy, systematic global coverage, and more straight forward processing. Also, since all of the satellite data in our experiments are assimilated continuously, we have chosen to remain with a 12-hour analysis cycle.

At each synoptic time (0000 GMT and 1200 GMT) a first guess at the state of the atmosphere based on a model forecast from the previous synoptic time is corrected on the basis of observational data. The cycle was initiated with a first guess field taken from the nature run for February 15, 1976. This provides a poorer first guess than the usual 12-hour forecast; it is comparable to starting with climatology. (The adjustment time to an asymptotic error level will be discussed in section 3.) The nature run was used to simulate observations at the lo- 
cations of the conventional surface, radiosonde, and ship stations from which 12-hourly reports were actually received at NMC during February 1976. By using this data to correct the first guess field constitutes the analysis part of the cycle. The analysis method employed is the successive correction method (SCM) generally credited to Cressman [1959]. At each synoptic time, seven successive scans with radii of $1200,1050,900$, $750,600,500$, and $400 \mathrm{~km}$ were performed. The field so created is used as the initial conditions for a 12-hour forecast to the next synoptic time. This forecast field is then used as the first guess field for the next analysis.

It is important to emphasize that the distribution of observations is realistic. The locations and times of the observations are identically those of the upper air station, surface station, and ship reports received at synoptic times at NMC during February 1979. When observational data were missing from the NMC reports, they were omitted from the simulated version. The grid point values from the nature run were interpolated both horizontally and vertically to the actual location of the reporting stations or ships. The interpolation was linear with distance in the horizontal and linear in the $\log$ of the pressure in the vertical.

A typical distribution of reporting surface stations is shown in Figure $2 a$ for 0000 GMT and Figure $2 b$ for 1200 GMT. Throughout the month there are approximately 4500 surface reports-at each synoptic time. At all times land-areas, with the exceptions of Africa and of polar regions, are well covered. Coverage over the oceans is generally poor; only the North Atlantic and North Pacific (the band from $20^{\circ} \mathrm{N}$ to $60^{\circ} \mathrm{N}$ ) show a substantial number of ship reports. (The coverage of these well-traveled ocean areas shows an interesting diurnal cycle: Relatively few reports are received from North Atlantic at 0000 GMT or from the Pacific at 1200 GMT).

The upper air stations (radiosondes plus a few specially instrumented aircraft) for $0000 \mathrm{GMT}$ and $1200 \mathrm{GMT}$ are shown in Figures $3 a$ and $3 b$, respectively. Approximately 800 reports are received at each synoptic time. Most of these come from North America and Eurasia; the oceans and the southern hemisphere are sparsely covered. Since Seasat furnished surface data only it cannot be expected to remedy this situation.

To create the 'observed' data we must add errors to the value obtained by interpolating from the model grid to the observational location. The errors added are meant to be representative of both instrument and sampling errors, with the latter being larger in magnitude. Sampling errors arise because the quantities observed are not the same as the quantities needed to specify the initial state of a GCM. The GCM calculation involves only scales greater than or equal to the grid mesh size. Subgrid scale phenomena are not explicitly represented; they are parameterized. On the other hand, observations are point measurements: Components at all scales contribute to the measured value. Since spectra of atmospheric variables show appreciable power at subgrid scales, a single observation does not give a good estimate of the value appropriate to a GCM grid point. This is true even if the location in space-time of the observation coincides with the grid point location. A good estimate requires enough observational data influencing a grid point value so that subgrid scale components may be effectively filtered out by properly averaging the available data.

The error to be added to the interpolated value is thus of the same magnitude as the error made by taking a single observation as representative of the grid box value. The magni- tude of this error will therefore depend on the size of the grid mesh. Estimates of the error value may be made on the basis of a number of recent studies of the spatial covariances of meteorological fields. From Wilcox and Sanders [1976] and Bruce et al. [1977] we estimate the appropriate rms temperature error to be $2.25 \mathrm{~K}$ while from Baver [1976] we estimate the rms errors in each component of the horizontal wind vector to be $4.5 \mathrm{~m} / \mathrm{s}$. All of these error values are relative to a grid spacing of about $400 \mathrm{~km}$, consistent with the models $4^{\circ} \times 5^{\circ}$ grid. We were unable to locate a similar study for surface pressure so for this variable we adopted the GARP error limits of $3 \mathrm{mbar}$. For simplicity, all errors were taken to be uniform random. It should be emphasized that these errors are not analysis errors; one would expect the analysis error to be less in data rich regions because each grid point is influenced by a number of observations so that the smaller scales tend to be filtered. The average analysis errors in the experiments are shown for selected regions and variables in Table 1. Errors are lowest over the well-observed Eurasian land mass. The North America verification region extends to $86^{\circ} \mathrm{N}$ and so includes a significant data sparse area making the errors somewhat larger than Eurasia. The analysis error for the United States alone is similar to Eurasia. All ocean areas exhibit substantially larger errors. Bengtsson and Morel [1974] suggested grid point analyses errors of $1.3 \mathrm{~K}$ and $2 \mathrm{~m} / \mathrm{s}$ over land. The raw temperature error given above $(2.25 \mathrm{~K})$ is consistent with theirs if one assumes that four radiosondes influence each grid point directly (i.e., are within a mesh length of the point). With the same assumption we estimate a wind analysis error over land of 2.6 $\mathrm{m} / \mathrm{s}$; we believe $2 \mathrm{~m} / \mathrm{s}$ is too low.

We have greatly simplified the structure of the error by taking it to be spatially uniform. For example, Bruce et al. [1977] show that the temperature error tends to be larger near the ground, decreases with height to about 500 mbar level and then increases again. One also expects horizontal variability to differ due to topographic inhomogeneities. We didn't feel that the actual error structure is sufficiently well known to justify such refinements. It is interesting to note that the analysis error exhibits spatial structure beyond what is introduced by the distribution of data points (viz. zonal wind at level $9\left(U_{9}\right)$ versus that at level $5\left(U_{3}\right)$ in Table 1 , though there also is somewhat more wind data at level 9 ( $\sim 945$ mbar) than level 5 ( $\sim 500$ mbar)). This is attributable to spatial differences in the quality of the first guess field supplied by the model 12-hour forecast.

In summary, we believe the errors introduced to be realistic. Though the surface pressure error is unrealistically large the density of surface stations in most regions makes the analyses error only slightly high. Insofar as the errors deviate from reality it is preferable that they be high since there is no way for these experiments to account for errors due to model physics or resolution.

Satellite assimilation. Four separate satellite assimilations were performed. In each, the control forecast-analysis cycle described above was duplicated. Three Seasat 'surface' wind experiments were performed in which the control run assimilated (1) error-free winds by the direct insertion method (PWDIM); (2) error-free winds by the successive correction method (PW-SCM); (3) winds to which were added nominal SASS wind speed and direction errors, by the SCM (EWSCM); (4) error-free temperature soundings following a Nimbus orbit, by the SCM, (PT-SCM).

In the Seasat assimilations, simulated scatterometer wind 
SURFACE STATIONS FEB. 1 '76 $02 \pm 3$

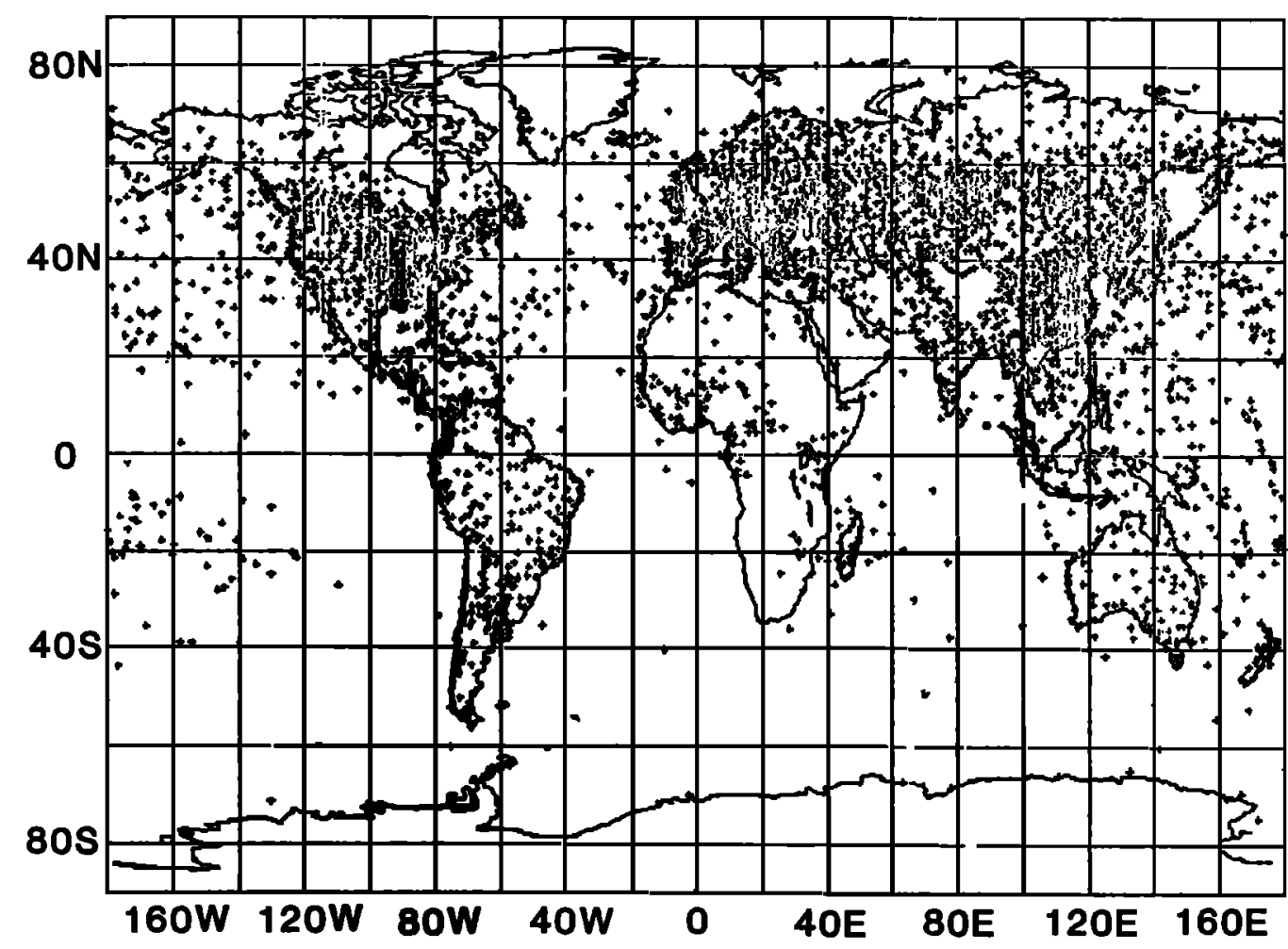

SUPFACE STATIONS FEB. $1 \cdot 76 \quad 12 \mathrm{Z} \pm 3$

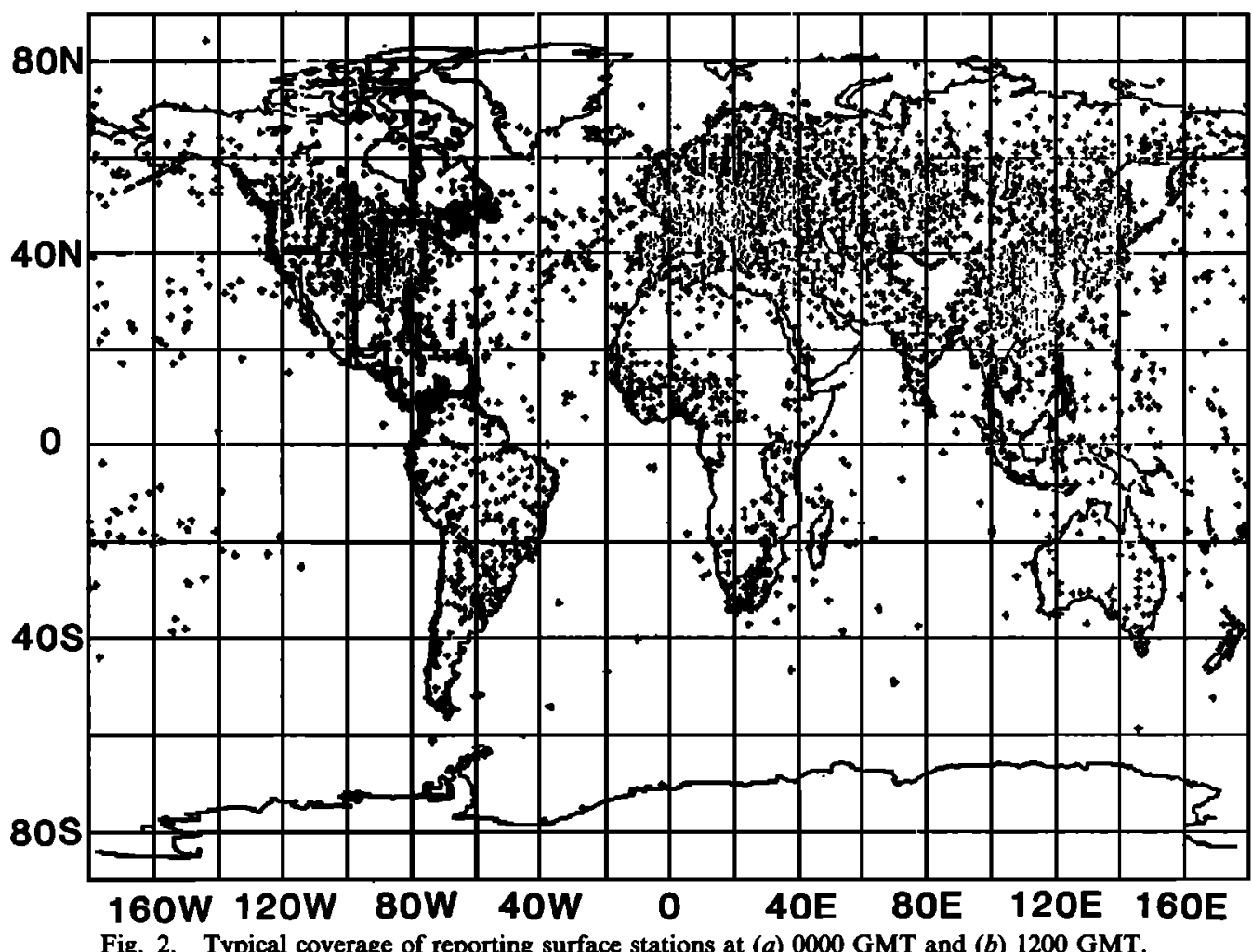

data is introduced into the control analysis/forecast cycle at each $10 \mathrm{~min}$ model time-step. Model grid points that fall the line of subsatellite points covered from time $t-5$. to $t+5$ within the scatterometer swath during a timestep are deter$\min$ is first determined. The scatterometer senses a swath on each side of the orbital track; each swath starts at a point 200 mined by simulating the expected Seasat 1 orbit. At time, $t, \quad \mathrm{~km}$ from the subsatellite point and extends out to $700 \mathrm{~km}$ 
UPPER- AIR STATIONS FEB. $1 \cdot 76 \quad 02 \pm 3$

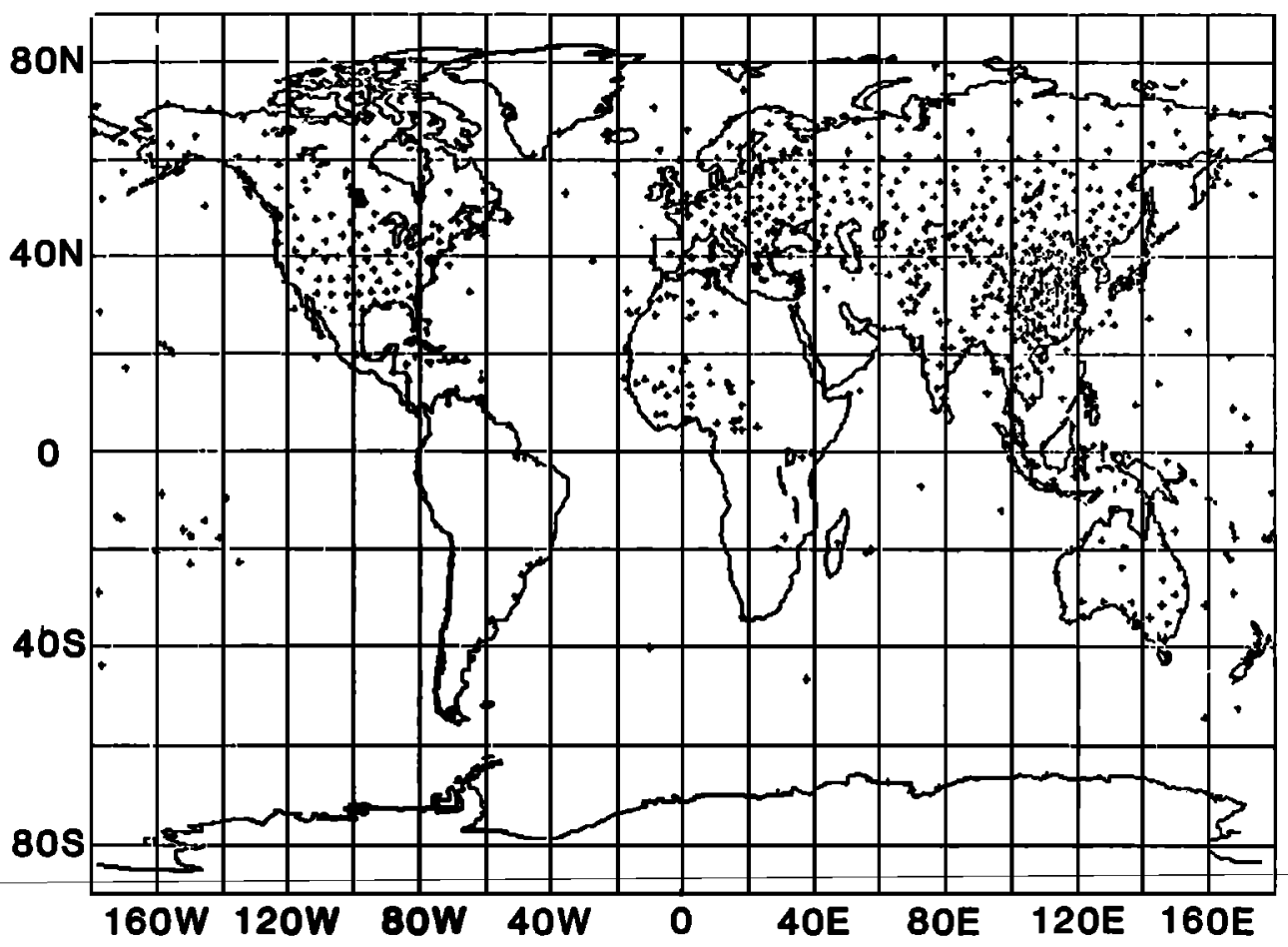

UPPER AIR STATIONS FEB. 1 '76 122 13

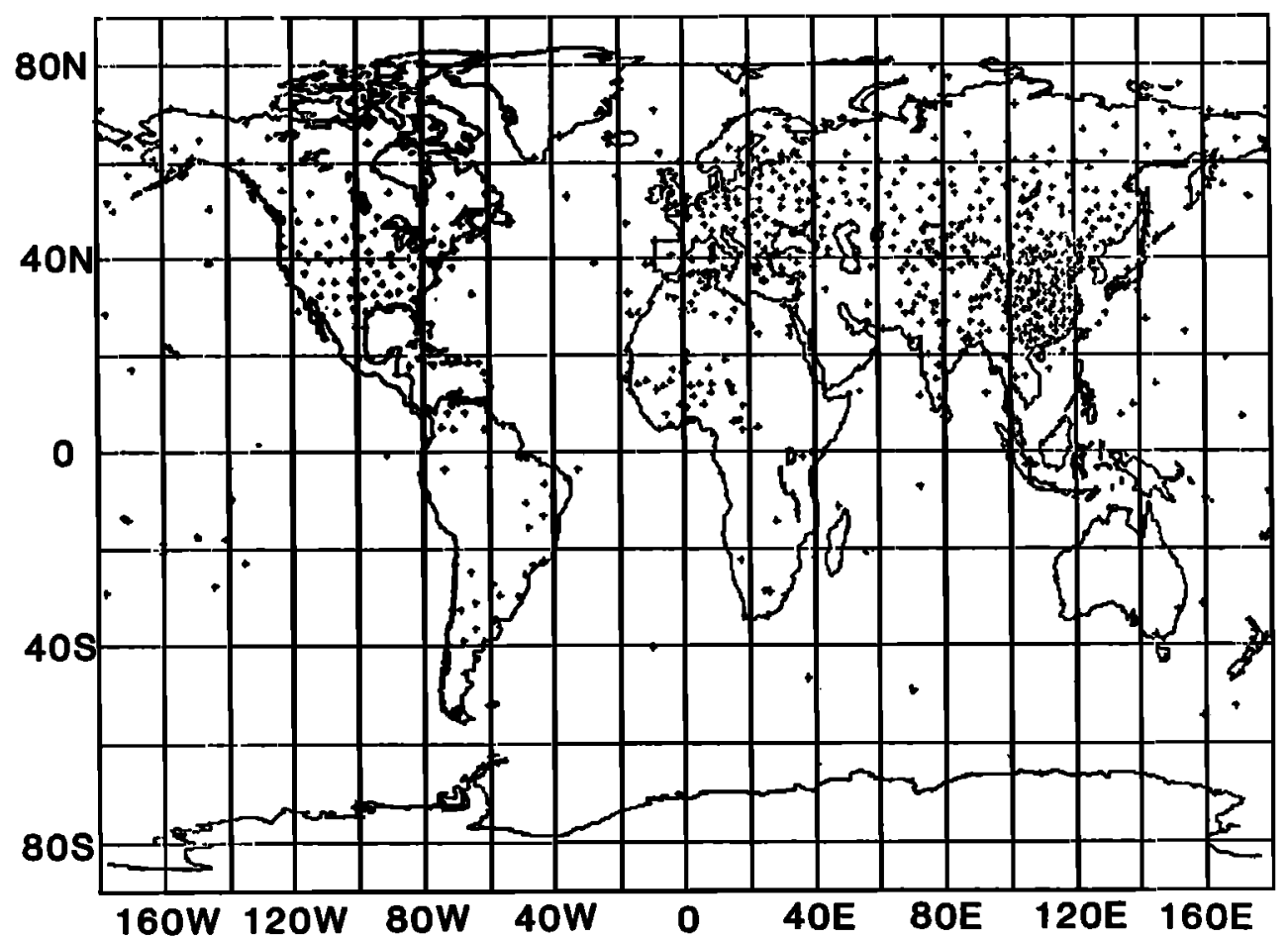

Fig. 3. Typical coverage of reporting upper air stations at (a) $0000 \mathrm{GMT}$ and (b) $1200 \mathrm{GMT}$.

from the subsatellite point. Figure $4 a$ shows a typical pattern of grid points covered in 3-hour period; Figure $4 b$ shows the total number of grid points covered in the 12-hour between synoptic times. In the experiment, data is inserted at ocean points only since the scatterometer does not provide wind data over land. When the scatterometer footprint is entirely over oceans, approximately 20 grid points are covered in each 10 min timestep. 
TABLE 1. Mean Analysis Error for the Period February 11 to February 24

\begin{tabular}{|c|c|c|c|c|c|c|c|c|}
\hline \multirow[b]{2}{*}{ Region } & \multicolumn{2}{|c|}{$T_{9}(\mathbf{K})$} & \multicolumn{2}{|c|}{$P_{\text {sfc }}$ (mbar) } & \multicolumn{2}{|c|}{$\mathrm{U}_{9}\left(\mathrm{~m} \mathrm{~s}^{-1}\right)$} & \multicolumn{2}{|c|}{$\mathrm{U}_{\mathrm{s}}\left(\mathrm{m} \mathrm{s}^{-1}\right)$} \\
\hline & $\begin{array}{l}\text { O000 } \\
\text { GMT }\end{array}$ & $\begin{array}{l}1200 \\
\text { GMT }\end{array}$ & $\begin{array}{l}0000 \\
\text { GMT }\end{array}$ & $\begin{array}{l}1200 \\
\text { GMT }\end{array}$ & $\begin{array}{c}0000 \\
\text { GMT }\end{array}$ & $\begin{array}{l}1200 \\
\text { GMT }\end{array}$ & $\begin{array}{l}0000 \\
\text { GMT }\end{array}$ & $\begin{array}{r}1200 \\
\text { GMT }\end{array}$ \\
\hline Eurasia & 0.9 & 0.9 & 0.7 & 0.7 & 0.9 & 0.9 & 2.3 & 2.3 \\
\hline North America & 1.2 & 1.2 & 0.7 & 0.9 & 1.0 & 1.1 & 2.2 & 2.4 \\
\hline North Atlantic & 1.1 & 1.1 & 0.9 & 0.9 & 1.6 & 1.6 & 3.1 & 2.9 \\
\hline North Pacific & 1.3 & 1.3 & 1.3 & 1.4 & 2.8 & 2.8 & 3.3 & 3.5 \\
\hline Tropical oceans & 1.1 & 1.1 & 0.9 & 1.0 & 2.7 & 2.8 & 7.8 & 8.0 \\
\hline South America & 2.1 & 2.1 & 1.5 & 1.5 & 3.7 & 3.8 & 11.9 & 12.0 \\
\hline
\end{tabular}

The simulated error-free wind data is assimilated into the model in two ways. In one experiment (PW-DIM), the direct insertion method (DIM) was used, and the wind components at level 9 at the appropriate grid points were simply replaced by the satellite wind components. The PW-DIM experiment is a baseline for evaluating the impace of other assimilation techniques. In a separate experiment (PW-SCM), the error free wind data were assimilated by successive correction [Cressman, 1959]. Basically, the same analysis scheme used in the control analysis is applied to the level 9 windfield at each insertion step; the wind components given as satellite data are treated as observations. The analysis procedure serves to extend the influence of the data to neighboring grid points including those land points that fall within the scan radii. The implementation of DIM and SCM in the GLAS GCM are described in detail by Ghil et al. [1979].

The implementation of a statistically based 'optimal interpolation' scheme [Gandin, 1963; Phillips, 1976; Ghil et al., 1977; Ghil et al., 1979] was considered and rejected. The SASS data tends to be uniformly distributed in space, and, out of ignorance, we are compelled to assume a uniform error structure in the data. In such a case the SCM is very similar to the optimal interpolation scheme, a point noted by Gandin [1963] (also see Ghil et al. [1977], who interpret the SCM as an optimal interpolation scheme with a diagonal covariance matrix). Since the expectation is that the results of statistical assimilation schemes would differ little from those for the SCM, and since such methods are much more expensive and difficult to implement [cf. Ghil et al., 1979], it was decided not to use them in this simulation study. We would expect that statistical methods will prove superior to the SCM when applied to actual scatterometer measurements because such methods are better able to compensate for complex error structure in the data as well as for patches of missing data.

The temperature sounding experiment (PT-SCM) simulated the addition to the control run of perfect temperature soundings, retrieved at the locations of actual Nimbus 6 HIRS and SCAMS soundings during February 1976. The soundings are grouped in 10-min intervals. Temperatures are simulated at mandatory pressure levels at the sounder locations by using the 'nature run' and the interpolation scheme documented in Halem et al. [1978]. The simulated temperatures were assimilated by the SCM as in Ghil et al. [1979].

Forecasts. Five sets of forecasts were made. One used initial conditions resulting from the control assimilation, while the other four were from initial conditions of the PW-DIM, PW-SCM, EW-SCM, and PT-SCM assimilation runs. Each set of forecasts consisted of five forecasts from 0000 GMT on days $5,10,15,10$, and 25 , except that the nominal wind error assimilation was run to day 15 so only three forecasts were possible. Five days appears to be the minimum separation that allows the statistics of successive forecasts to be independent. Each forecast was verified against the nature run.

\section{Results of CONTROL Assimilation AND FORECASTS}

In this section we will describe some of the characteristics of the control assimilations and forecasts. We defer comparisons of the control and satellite results to the following sections. All variables in all regions show a large initial error due to the poor set of initial conditions used as the first guess field. These analysis errors are sharply reduced after the second synoptic insertion (day 0, 1200 GMT) and, in most cases, reach their asymptotic values in about 5 days (cf. Table 1). All oceans have sparse wind and upper, air data so that the winds take approximately 10 days to reach their asymptotic values.

Because of the identical twin nature of these experiments (i.e., the forecasts and assimilations are done with the identical model physics and resolution used to generate the nature run) there is the danger that the errors and error growth curves will be unrealistically low. It is difficult to assess the effect of this on the possible impact of additional data: On the one hand, an unrealistically good control forecast will be hard to improve upon; on the other hand, an unrealistically good satellite assimilation will do a better job of advecting the added data.

The mean analysis errors for the period February 11 to February 24 is shown for all regions and all variables studied in Table 1. Of particular interest is the realism of the level 9 windfield in the control analysis, since this is the field most directly corrected by the assimilation of wind data. The control field surface wind errors may be compared with estimates of the errors in operational marine surface windfields. Cardone et al. [1976] evaluated the accuracy of surface winds diagnosed from operational Fleet Numerical Weather Center (U.S. Navy) analysis products against standard synoptic wind measurements at the Ocean Station vessels in the North Atlantic. In 756 comparisons the root mean square (scalar) wind difference between analyses and weather ship winds was found to be $4.1 \mathrm{~m} / \mathrm{s}$. The true error in the conventional surface windfield analyses was estimated to be about $3.3 \mathrm{~m} / \mathrm{s}$, when the errors in the standard weather ship wind measurements were accounted for.

The recent deployment of NOAA data buoys around the United States coastline has provided opportunity for more accurate assessment of marine windfield errors there. Overland and Gemmill [1977] evaluated four different ways of specifying surface winds from an operational NMC analysis, against data buoy measurements in the New York Bight. The best diagnostic technique yielded scalar wind errors of about $2.4 \mathrm{~m} /$ s. Cardone [1978] extended that study to all buoys along the U.S. east, gulf, and west coast and found rms errors in wind speed of $2.9 \mathrm{~m} / \mathrm{s}$ for all areas combined (2092 cases). The above studies are quite consistent, verifying the expected degradation in marine windfields as one proceeds further away from the coast. In the light of these studies, the wind errors shown in Table 1 for the control appear to be realistic. 

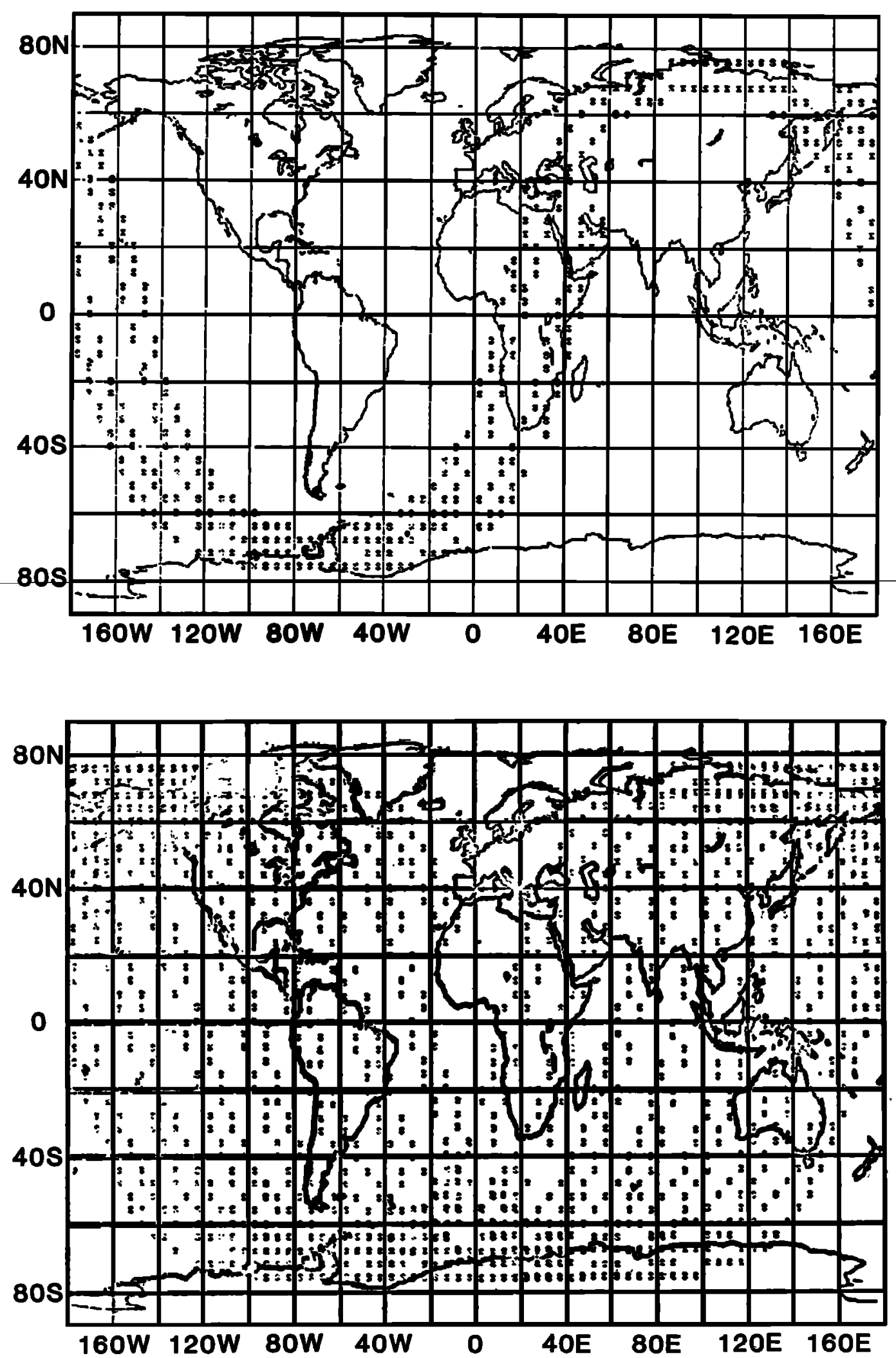

Fig. 4. Model grid points intercepted by the simulated scatterometer scan pattern for the Seasat-1 orbit segments for February 9. (a) 2100-2400; (b) 1200-2400 GMT. (No data is obtained for points over land.)

Figure 10 shows the spatial distribution of the error in the control level 9 windfield. The plot shows both the magnitude and direction of the vector difference in level 9 wind between control and nature, at 0000 GMT February 10. It is typical and shows the spatial coherency to the error patterns; data gaps produce large areas of the oceans where vector errors as high as 7-8 m/s are evident. Figure 10 is remarkably similar to difference plots described by Cardone et al. [1980], which were 

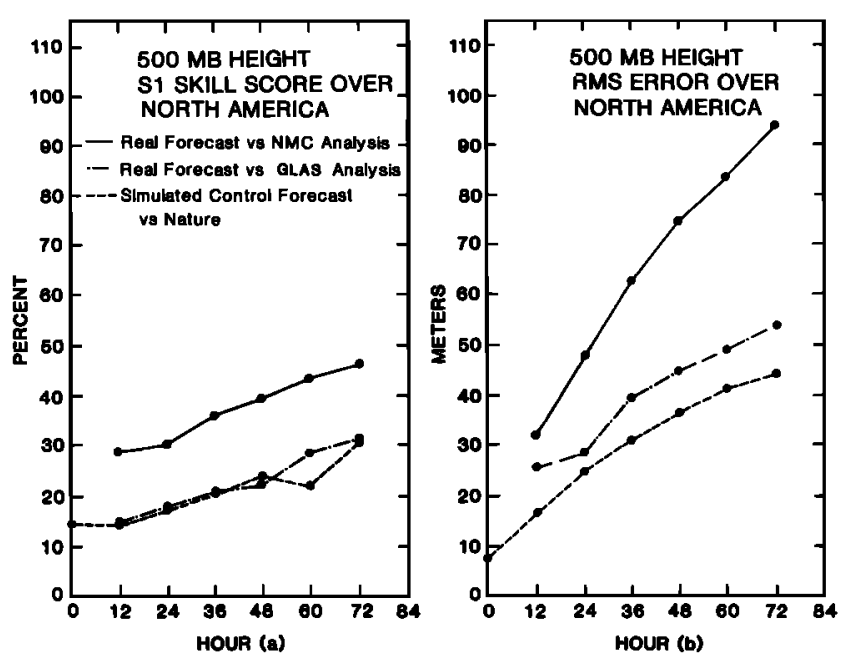

Fig. 5. Comparison of actual and simulated forecast error growth: dashed curve, simulated control forecast versus nature; dotdashed curve, real forecast versus GLAS analysis; solid curve, real forecast versus NMC analysis.

derived from analysis of real extratropical cyclones in the North Pacific.

Figure 5 shows the error growth averaged over the five control cases of the 500 mbar geopotential height over North America. The other curves in Figure 5 are the average error in 11 real forecasts made during February 1976 with the same model used in the present study [Quirk and Atlas, 1977]. For these real forecasts the errors are much higher when the verification is against the NMC analysis than when it is against an analysis generated with the same model and grid. The simulation study error growth rates are comparable to those that ob- tain for the real forecasts when these are verified against the model generated analysis.

We conclude that the errors and error growth rates in our experiments are realistic but note that we are able to reach this conclusion by choosing favorable standards of verification: The simulation error is increased by comparing with the nature run rather than an analysis and the real error is reduced by comparing with an analysis derived from the same model.

\section{COMParison OF CONTROL AND SATEllite FORECASTS}

In this section, the 72-hour forecasts made from control and satellite initial states at 0000 GMT on February 5, February 10, February 15, February 20, and February 25 are compared. The comparisons are made in terms of growth of rms error in level 9 zonal wind $\left(U_{9}\right)$, level 5 zonal wind $\left(U_{5}\right)$, and surface pressure $\left(\mathbf{P}_{\mathrm{s}}\right)$ for each case. In addition, subjective evaluation of isobaric sea level pressure charts is given for the control and SCM forecasts made from February 10.

The results of the PW-DIM experiment generally confirmed our expectation that direct insertion of level 9 winds would have no significant impact on analyses and forecasts. This experiment will not be considered further. The assimilation of error free level 9 winds by successive correction (PWSCM) resulted in discernable positive impacts on analyses and forecasts.

Table 2 displays rms errors relative to nature in $P_{B}$ and $U_{5}$ for individual forecasts from the control, PW-SCM and PTSCM initial states, with the statistics sorted by day and region. Statistics for $\mathrm{U}_{9}$ and for other regions (Eurasia, North Atlantic, South America) were similarly prepared and studied. The errors for day 0 represent the errors in the initial states. Because of the small sample size, we did not attempt to establish

TABLE 2. Comparison of 3-Day Forecast Surface Pressure (Top) and Level 5 Zonal Wind (Bottom) Errors from Control (C), Perfect Wind (SCM), and Perfect Temperature Sounding (PT) Initial States

\begin{tabular}{|c|c|c|c|c|c|c|c|c|c|c|c|c|c|c|c|c|}
\hline \multirow[b]{2}{*}{ Region } & \multirow[b]{2}{*}{ Day } & \multicolumn{3}{|c|}{ February 5} & \multicolumn{3}{|c|}{ February 10} & \multicolumn{3}{|c|}{ February 15} & \multicolumn{3}{|c|}{ February 20} & \multicolumn{3}{|c|}{ February 25} \\
\hline & & $\mathbf{C}$ & SCM & PT & $\mathbf{C}$ & SCM & PT & C & SCM & PT & C & SCM & PT & $\mathbf{C}$ & SCM & PT \\
\hline \multicolumn{17}{|c|}{ Surface Pressure Error (mbar) } \\
\hline Latitude, $30^{\circ}$ to $86^{\circ}$ & 0 & 0.9 & 0.7 & 0.8 & 0.8 & 0.7 & 0.6 & 0.7 & 0.7 & 0.6 & 0.9 & 0.7 & 0.7 & 0.8 & 0.8 & 0.6 \\
\hline Longitude, $0^{\circ}$ to $165^{\circ}$ & 1 & 2.5 & 2.1 & 2.8 & 2.7 & 2.5 & 2.2 & 1.5 & 1.4 & 1.2 & 1.7 & 1.3 & 1.3 & 2.6 & 2.3 & 2.1 \\
\hline Land & 2 & 3.6 & 2.8 & 3.7 & 3.5 & 2.9 & 2.5 & 2.0 & 1.9 & 1.9 & 2.5 & 2.1 & 2.0 & 3.2 & 3.8 & 3.2 \\
\hline (North America) & 3 & 3.4 & 2.9 & 3.3 & 4.2 & 3.1 & 3.5 & 2.6 & 2.5 & 2.5 & 3.8 & 3.1 & 3.3 & 3.9 & 4.1 & 3.3 \\
\hline Latitude, $30^{\circ}$ to $86^{\circ}$ & 0 & 2.0 & 1.0 & 1.7 & 1.5 & 1.0 & 1.0 & 1.2 & 0.9 & 0.9 & 1.3 & 1.0 & 0.9 & 1.2 & 1.0 & 0.9 \\
\hline Longitude, $275^{\circ}$ to $60^{\circ}$ & $\mathbf{l}$ & 4.3 & 3.4 & 3.7 & 2.9 & 2.1 & 2.1 & 1.7 & 1.7 & 1.3 & 2.7 & 2.0 & 1.3 & 2.0 & 2.0 & 1.3 \\
\hline Water & 2 & 4.5 & 3.7 & 4.0 & 3.9 & 2.8 & 3.0 & 2.5 & 2.4 & 2.0 & 3.4 & 2.9 & 2.0 & 2.5 & 3.1 & 1.7 \\
\hline (North Pacific) & 3 & 5.4 & 4.6 & 5.1 & 4.8 & 3.2 & 4.0 & 3.4 & 2.7 & 2.5 & 3.9 & 3.2 & 3.0 & 3.1 & 3.7 & 2.6 \\
\hline Latitude, $26^{\circ}$ to $+26^{\circ}$ & 0 & 1.0 & 1.0 & 1.0 & 1.0 & 0.9 & 0.9 & 0.9 & 0.8 & 0.7 & 0.9 & 0.9 & 0.7 & 0.9 & 0.8 & 0.8 \\
\hline Longitude, $0^{\circ}$ to $355^{\circ}$ & 1 & 1.6 & 1.7 & 1.5 & 1.5 & 1.4 & 1.4 & 1.3 & 1.3 & 1.2 & 1.3 & 1.4 & 1.2 & 1.2 & 1.2 & 1.1 \\
\hline Water & 2 & 1.5 & 1.7 & 1.6 & 1.6 & 1.5 & 1.4 & 1.3 & 1.3 & 1.3 & 1.4 & 1.3 & 1.2 & 1.4 & 1.5 & 1.3 \\
\hline (Tropical Oceans) & 3 & 1.9 & 1.7 & 2.2 & 1.8 & 1.7 & 1.5 & 1.5 & 1.5 & 1.4 & 1.5 & 1.4 & 1.3 & 1.4 & 1.5 & 1.5 \\
\hline \multicolumn{17}{|c|}{ Level 5 Zonal Wind Error $(m / s)$} \\
\hline Latitude, $30^{\circ}$ to $86^{\circ}$ & $\mathbf{0}$ & 3.4 & 2.0 & 2.1 & 2.3 & 1.6 & 1.6 & 2.2 & 1.4 & 0.9 & 2.4 & 1.4 & 1.4 & 2.4 & 1.4 & 1.4 \\
\hline Longitude, $0^{\circ}$ to $165^{\circ}$ & 1 & 3.8 & 3.0 & 2.9 & 4.6 & 3.8 & 3.5 & 2.3 & 1.9 & 1.4 & 3.6 & 2.2 & 2.2 & 3.8 & 3.6 & 2.4 \\
\hline Land & 2 & 5.5 & 4.5 & 5.0 & 7.2 & 5.4 & 4.8 & 3.0 & 2.8 & 2.4 & 4.3 & 3.6 & 2.8 & 6.0 & 6.0 & 4.2 \\
\hline (North America) & 3 & 7.1 & 5.3 & 6.6 & 8.3 & 7.0 & 6.7 & 3.9 & 4.3 & 3.6 & 5.3 & 4.7 & 3.5 & 8.2 & 7.0 & 5.2 \\
\hline Latitude, $30^{\circ}$ to $86^{\circ}$ & $\mathbf{0}$ & 8.2 & 5.6 & 6.5 & 4.4 & 3.4 & 2.7 & 2.8 & 2.5 & 1.6 & 3.1 & 2.6 & 1.5 & 3.5 & 3.9 & 1.6 \\
\hline Longitude, $275^{\circ}$ to $60^{\circ}$ & 1 & 8.2 & 5.9 & 7.0 & 4.1 & 3.6 & 3.4 & 2.8 & 2.5 & 2.3 & 3.6 & 3.3 & 2.1 & 4.1 & 3.9 & 2.0 \\
\hline Water & 2 & 8.5 & 6.8 & 7.3 & 5.1 & 3.9 & 3.8 & 3.4 & 3.3 & 2.7 & 4.8 & 4.2 & 3.2 & 4.8 & 4.5 & 2.0 \\
\hline (North Pacific) & 3 & 8.4 & 7.4 & 6.7 & 6.4 & 5.0 & 4.4 & 4.0 & 4.3 & 3.3 & 6.2 & 4.8 & 4.4 & 6.0 & 5.1 & 2.0 \\
\hline Latitude, $26^{\circ}$ to $+26^{\circ}$ & $\mathbf{0}$ & 9.2 & 8.6 & 8.3 & 9.3 & 8.7 & 8.3 & 8.0 & 7.6 & 7.0 & 7.6 & 6.8 & 6.5 & 7.7 & 7.1 & 6.2 \\
\hline Longitude, $0^{\circ}$ to $355^{\circ}$ & $\mathbf{1}$ & 9.5 & 9.5 & 8.3 & 8.3 & 8.7 & 8.0 & 7.8 & 8.0 & 7.3 & 7.4 & 7.3 & 6.6 & 8.3 & 7.7 & 6.3 \\
\hline Water & 2 & 9.7 & 9.3 & 7.8 & 8.5 & 8.9 & 8.6 & 8.0 & 7.8 & 7.4 & 8.1 & 7.3 & 6.4 & 8.4 & 7.9 & 7.2 \\
\hline (Tropical Oceans) & 3 & 9.7 & 9.7 & 8.9 & 9.4 & 9.1 & 8.9 & 8.6 & 8.3 & 8.1 & 8.6 & 7.8 & 7.2 & 8.3 & 8.1 & 7.7 \\
\hline
\end{tabular}



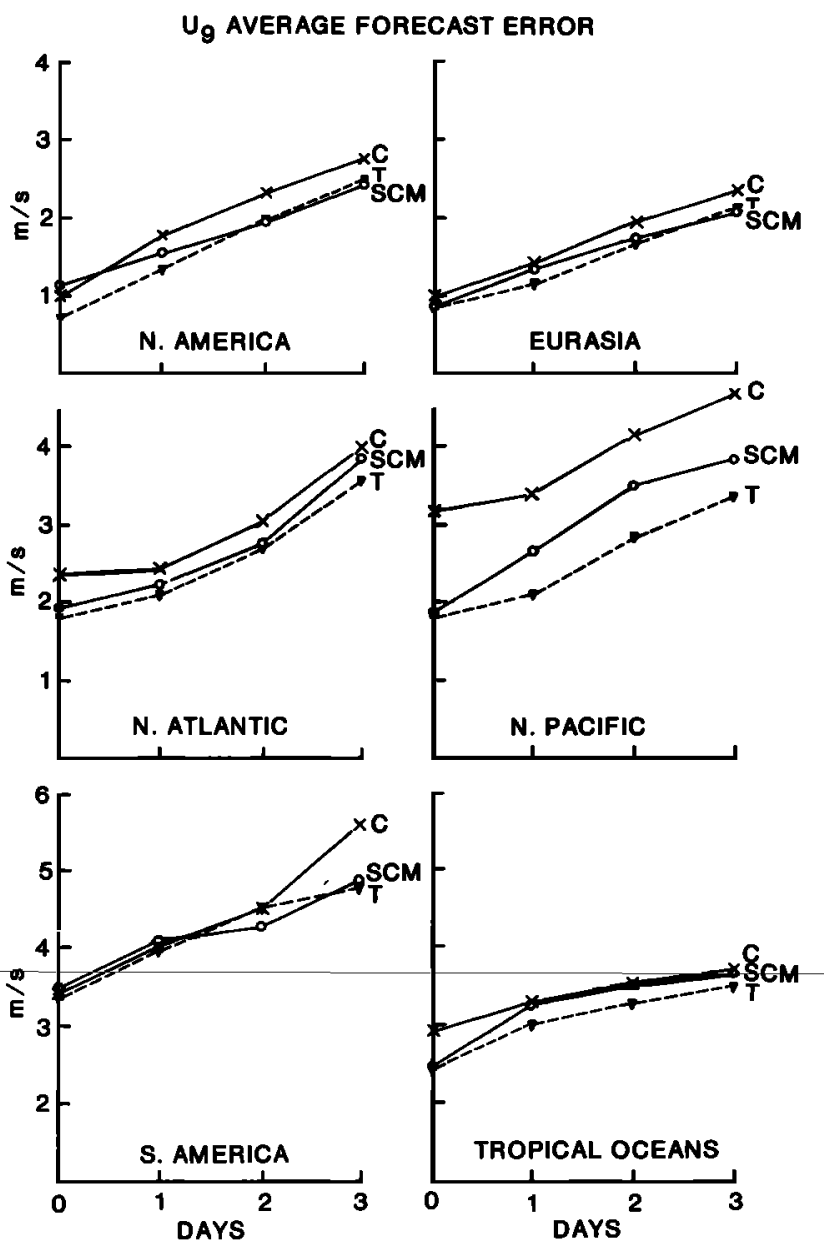

Fig. 6. Growth of averaged level 9 zonal wind errors (rms) over indicated regions, in forecasts made from control (C), Seasat SCM, and perfect temperature (T) initial states.

the statistical significance of the average differences between the control and satellite forecast; however, the average growth of error is shown graphically for all areas studied in Figures 6, 7 , and 8 for $U_{9}, P_{s}$, and $U_{5}$, so that relative differences in forecast errors can be assessed subjectively.

The most significant and consistent positive impacts were found to be in the level 9 wind field analysis (day 0 ) over the North Pacific where average $U_{9}$ rms errors decreased by $40 \%$ relative to the control analysis error. $U_{9}$ initial analysis errors also decreased by about $20 \%$ over the North Atlantic, North America, and tropical ocean regions. Initial surface pressure errors in the PW-SCM fields were lower than the control fields by about $30 \%$ in northern hemisphere oceans; however, control errors are already quite low there. Average improvements in the $U_{5}$ PW-SCM initial fields were found over all regions except tropical oceans and South America, where only slight impacts were found.

The forecasts made from error free wind SCM analyses are generally more skillful than corresponding control forecasts by margins equivalent to relative differences in the initial states. This can be seen most easily in Figures 6, 7, and 8 . The most consistent impacts in surface forecasts were found over the North Atlantic: errors in three day forecasts were lowered in all five cases for $U_{9}$ and in four out of five cases for $P_{\mathrm{g}}$. Only a slight average forecast improvement was noted in other regions, although individual cases showed substantial positive impacts.
In view of the positive impacts in the statistics of the $P W$ SCM forecast runs, the individual cases were studied in detail to assess the nature and utility of the forecast differences in terms of synoptic scale meteorological systems. The forecast differences over the Pacific Ocean from day 10 are typical of what was found and sample results are presented here.

Figure 9 compares the control and PW-SCM sea level pressure 3-day forecasts made from day 10 initial states with nature over the North Pacific Ocean. The initial analyses are not shown since they are quite similar in appearance, though the rms statistics show that the PW-SCM analysis is slightly closer to nature than the control analysis. It should be recalled that both control and PW-SCM pressure fields at 0000 GMT day 10 have benefited from the rather numerous simulated ship report pressures (see Figure 2) assimilated in the conventional data analysis procedure. However, the 72-hour forecasts of sea level pressure from control and PW-SCM initial states do show important differences. Most striking are the improvement in the intensity and placement of the intense extratropical cyclone in the gulf of Alaska shown in the PW-SCM forecast and the spurious low pressure center off Newfoundland in the control. A smaller but noticable improvement may also be seen in the isobar pattern associated with the storm near $40^{\circ} \mathrm{N}, 160^{\circ} \mathrm{W}$.

The spatial distributions of the level 9 wind error in the control and PW-SCM initial states at day 10 are compared in Figure 10. It is seen that the errors are significantly lowered in

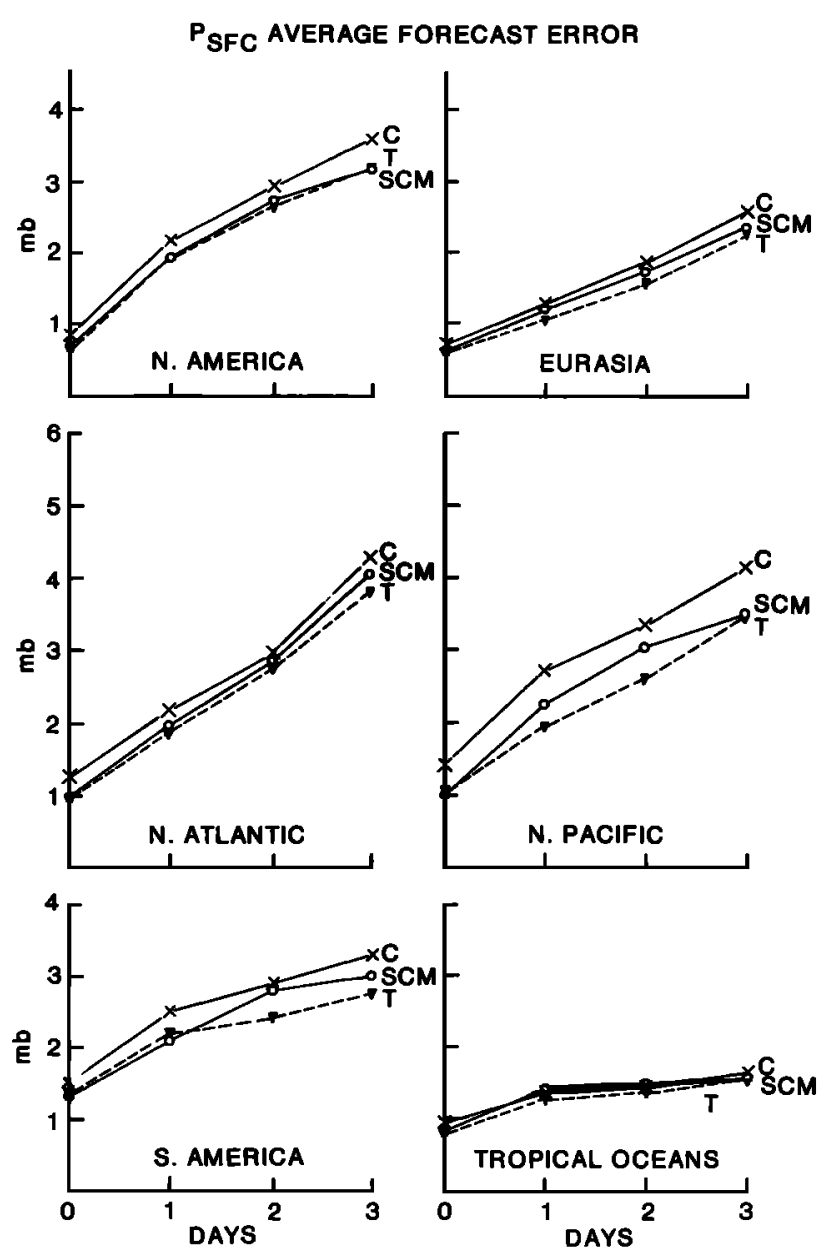

Fig. 7. Same as Figure 6, except for sea level pressure rms errors. 

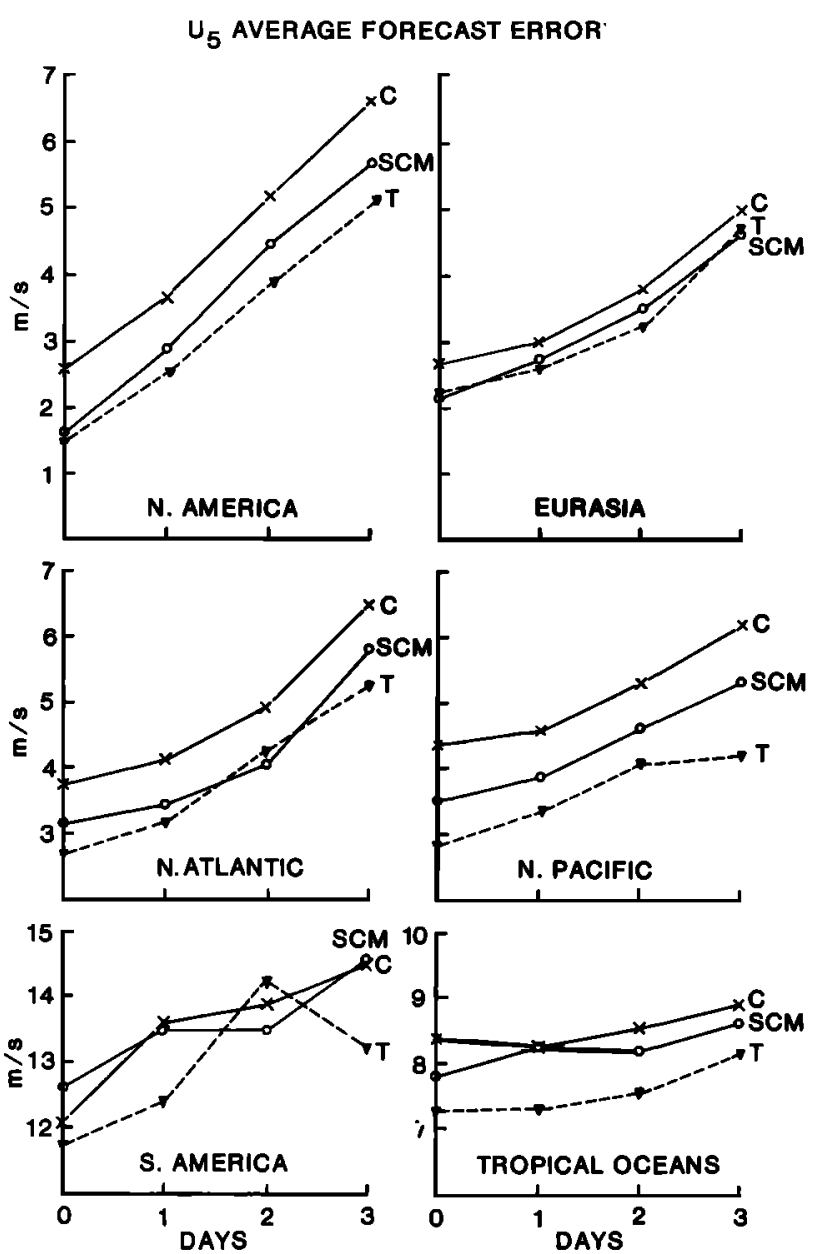

Fig. 8. Same as Figure 6, except for level 5 zonal wind rms errors.

the mid-latitude central and eastern North Pacific and that in addition to a general lowering of the level 9 wind error, the PW-SCM run has removed much of the systematic error in the control field due to the large data gaps there.

Impacts of the type exemplified above characterized forecasts from other days as well. It was apparent also that the impacts favored the eastern North Pacific Ocean where Seasat SCM forecast pressure analyses revealed consistently better forecasts of the intensity and placement of extratropical cyclones. This feature of the simulations may be related to the poor coverage of conventional data in the North Pacific, relative to the North Atlantic and continental regions, and to the fact that the simulated Seasat orbit favored the insertion of simulated Seasat wind data over the Pacific during the 6-hour period prior to $0000 \mathrm{GMT}$, which was the initial time for all forecast simulations (see Figure 4).

The PT-SCM experiment was conducted to provide an indication of the relative impact of surface wind data compared to sounder data, when both sets of observations could be considered to be error free. Most previous observing system simulation experiments have in fact dealt with sounders. While the earlier studies have tended to be quite optimistic regarding the potential impact of sounder derived temperatures on NWP, much of the optimism probably stemmed from unrealistic control experiments and the assumption of sounder errors much lower than have been attained operationally. Recent studies with real data have shown that sounders can have small but statistically significant beneficial impacts on weather forecasts, though these studies disagree on the precise magnitude and importance of these impacts [Ghil et al., 1979; Tracton et al., 1980]. The impacts appear to be highly sensitive to the quality and quantity of data, to the assimilation method, and to the forecast model [Tracton et al., 1981; Atlas et al., 1981]. Ghil et al. [1979] found that Nimbus sounder data gave 5-7\% improvement in rms measures of forecast skill over North America. Since they used the same GLAS GCM and the same time-continuous SCM assimilation procedure as in our study, we may use their results to evaluate the realism of our simulation methodology even while recognizing that the implications of these results for NWP are still controversial.

The results of our simulated perfect Nimbus sounding SCM experiment can be seen in Table 2 and Figures 6, 7, and 8 . In general, the impacts found were comparable to those of the PW-SCM experiment. The only different evident is that the sounding data is slightly more effective than the surface wind data in controlling growth of level 5 forecast wind errors. Within the context of our experiment, the two data types appear to have equivalent value in reducing surface pressure errors. The perfect sounding produced about a $10 \%$ improvement in sea level pressure (rms) forecast errors over North America. Compared to the results of less realistic observing system simulation experiments, this appears to be a more reasonable upper limit to impacts to be expected from sounder data.

\section{Concluding Discussion}

If simulation studies are to provide an accurate indication of how the simulated data will influence forecasts in the real world, it is crucial that their error characteristics be realistic. By introducing data at the actual observing locations we ensure that the distribution of error resulting from analysis based on conventional data is realistic. This is especially important in assessing the impact of satellite data since such data produces benefits by filling in data gaps rather than reducing the overall error level. The magnitude of the error attached to temperature and wind measurements was determined from estimates of sampling errors due to spatial variability of these fields. The values are therefore a function of the model grid size. The successive correction method of analysis allows many observations to influence a single grid point so the analysis error is less than the observational errors. The analysis errors in our study appear to be realistic with the exception of the surface pressure. However, reducing the surface pressure error to a more realistic level would probably make little difference since this error is already small compared with that in other variables.

The rate of error growth also appears to be realistic, as judged by a comparison with real forecast errors. As noted above, the magnitude of forecast errors is quite sensitive to the standard of comparison: verification against an analysis made with the GLAS forecast model (and grid) yields lower 'errors' than verification against the NMC analysis. In addition, the simulation study errors are made larger by comparing to the nature run rather than an analysis field.

The small sample size of the simulated Seasat forecasts makes conclusive statistics impossible but particular cases show substantial impact. Synoptic examination of these cases shows that these influences depend on the addition of level 9 wind data altering specific features of the initial state rather than on a uniform small improvement to the field. This in- 
SEA LEVEL PRESSURE - DAY 13

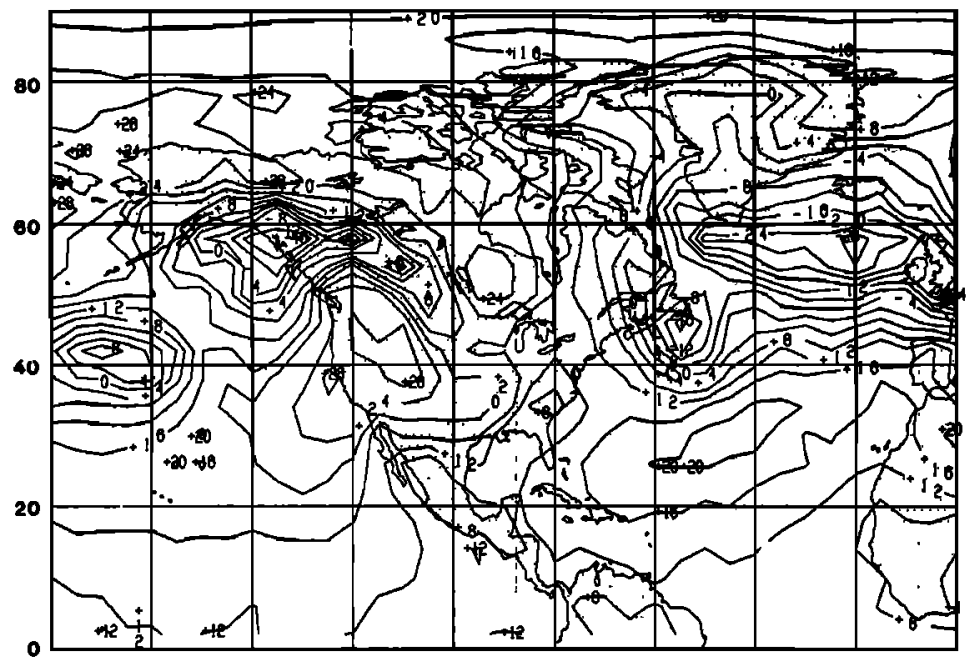

CONTROL FORECAST

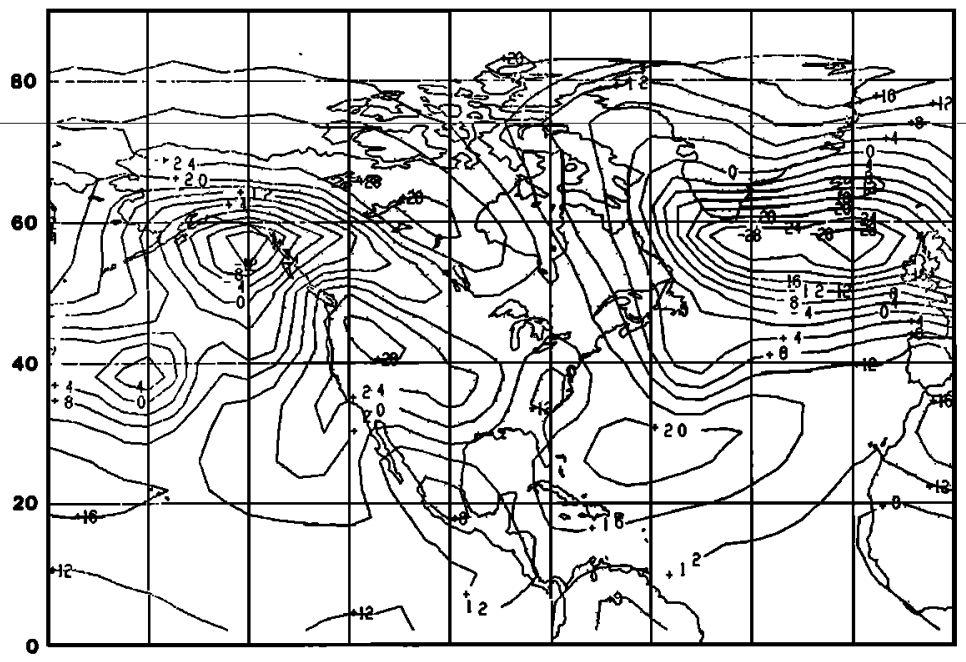

NATURE

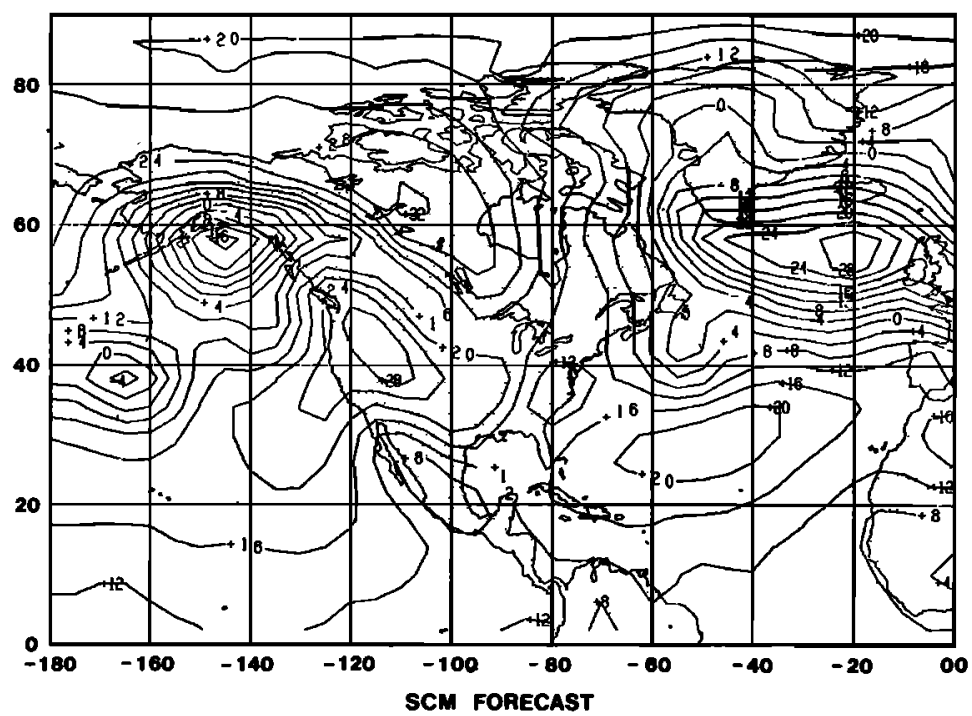

Fig. 9. Distribution of sea level pressure in control (upper) and Seasat SCM (lower) 72-hour forecasts from day 10 and in verifying nature field (middle) at day 13. 


\section{LEVEL 9 WIND ERRORS - DAY 10}

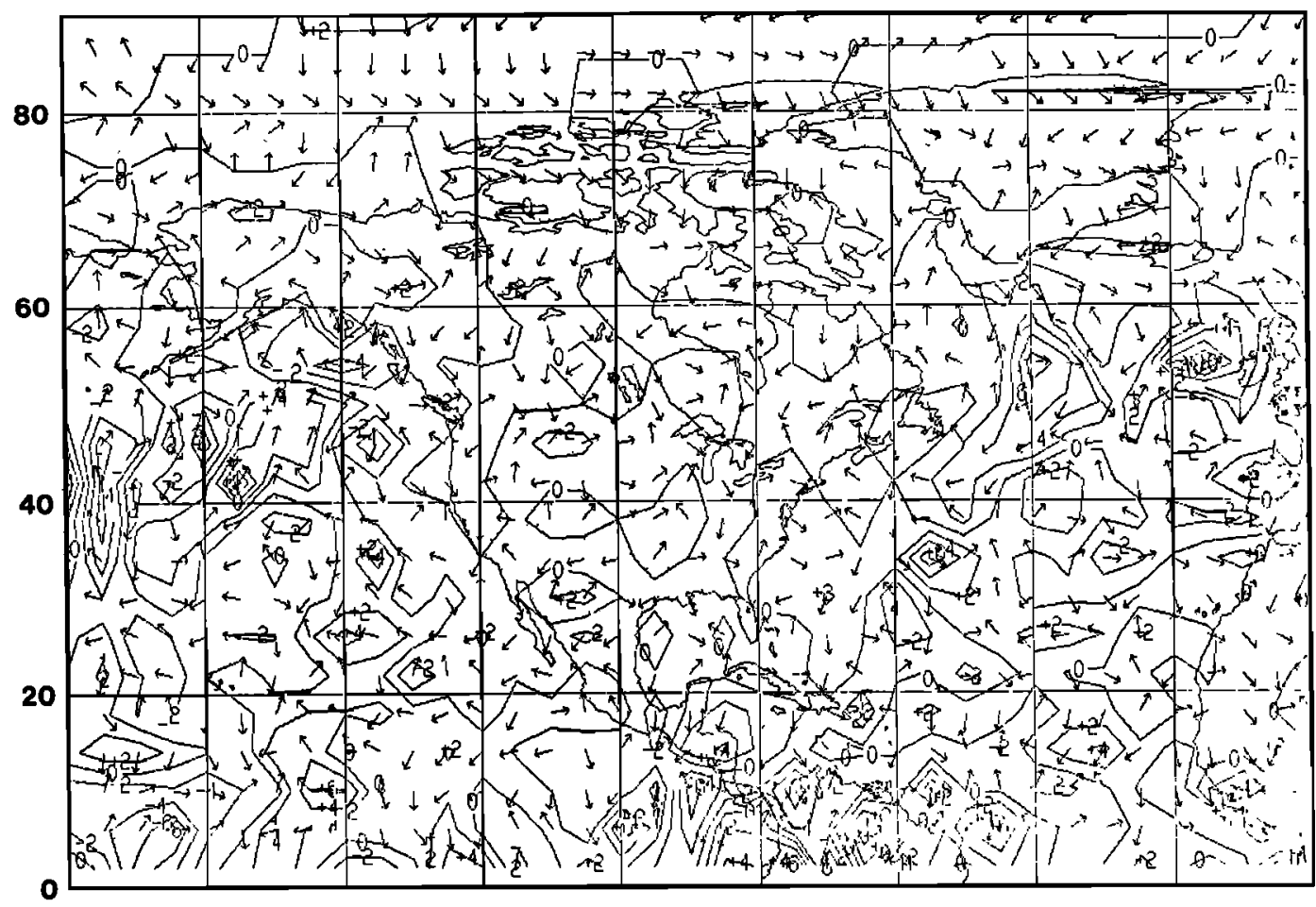

CONTROL vs NATURE

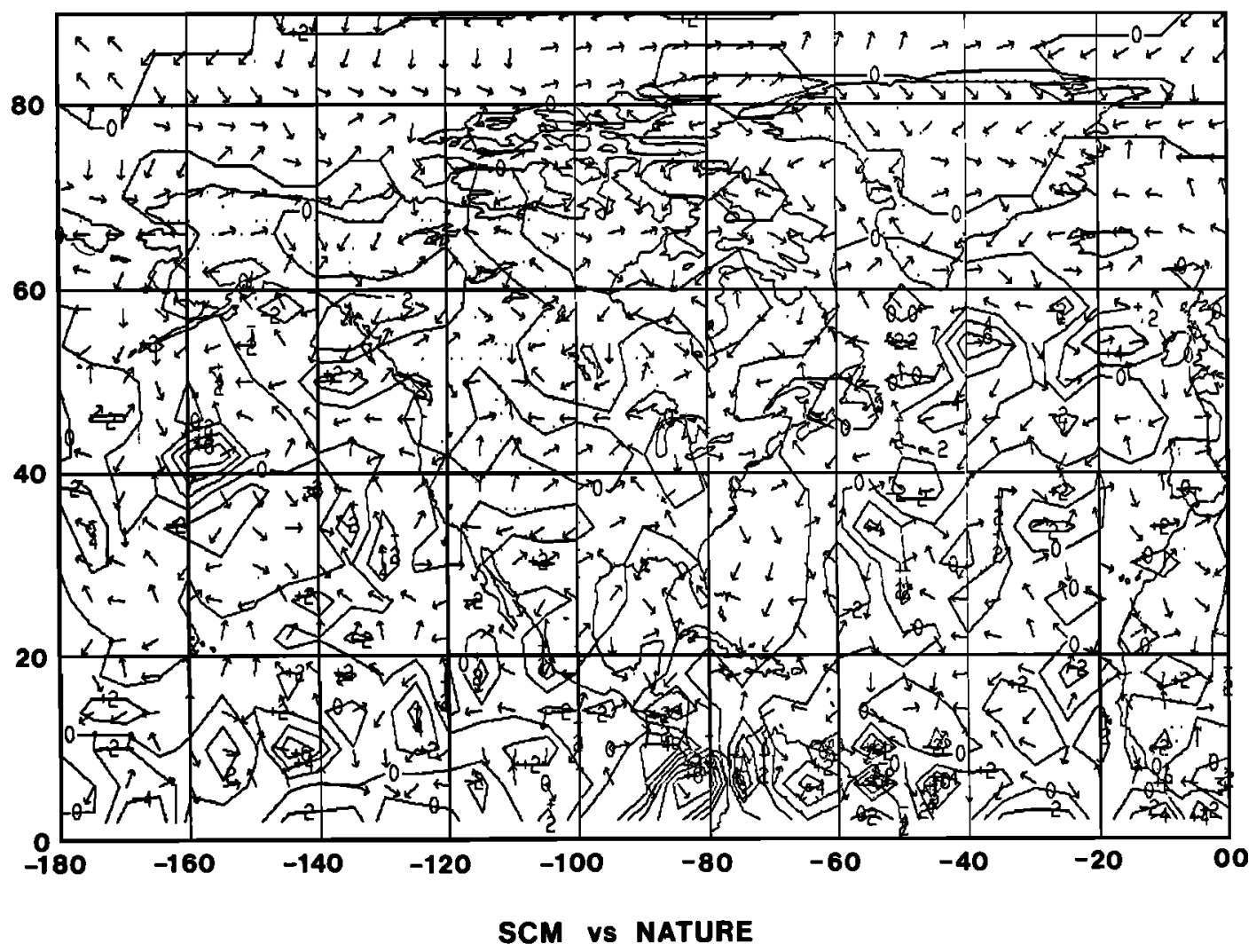

Fig. 10. Comparison of (a) control-nature and (b) Seasat-nature level 9 vector wind difference fields at day 10. 

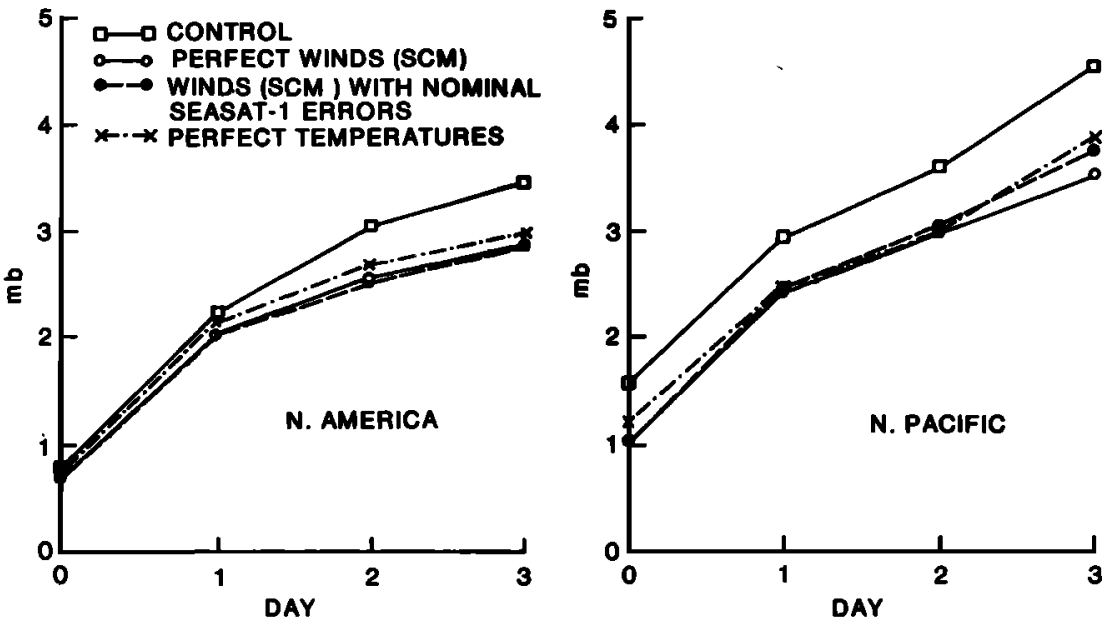

Fig. 11. Growth of averaged sea level pressure errors (rms) over North America and the North Pacific, in forecasts from control, Seasat SCM perfect wind, and Seasat SCM winds with errors, initial states (forecasts from February 5, 10, and 15 only).

creases our confidence that such impacts are not simply the result of a lucky random change.

The idealized error free wind experiments of course over estimate the positive impact to be expected from real Seasat 1 data. However, a limited SCM experiment was performed to assess the effect of nominal errors on the satellite winds ( $\pm 2 \mathrm{~m} / \mathrm{s}$ in speed, $\pm 20^{\circ}$ in direction, normally distributed). The results of that experiment are compared to the error free experiment in Figure 13. Evidently, for the fairly dense distribution of remotely sensed winds, the SCM assimilation is very effective at removing errors that are uncorrelated. Actual scatterometer wind data is likely to have a more complicated error structure, but we may speculate that the data can significantly impact forecasts if the errors are as small overall as the above, and if a good enough (though not necessarily optimal) assimilation scheme is used.

A comparison of the PW-SCM and PT-SCM experiments suggests that surface wind data has the same potential impact as temperature sounders, when both sets of observations are error free, especially over and downstream of the eastern North Pacific and North Atlantic basins. Indirect support for this result is provided by Blackmon et al. [1980]. They show from observational data that over the eastern sides of the northern hemisphere oceans the 500 mbar height is much more strongly correlated with $1000 \mathrm{mbar}$ height than with $1000-500$ mbar thickness and infer that surface (1000 mbar) data would play an important role in the determination of mid tropospheric structure. Satellite sounding data are of greatest potential over continents, where Blackmon et al. show that $\mathbf{5 0 0}$ mbar height is more strongly correlated with 1000-500 thickness than with 1000 mbar height. However, over continents, sounding data are largely redundant with conventional radiosondes.

The mechanism which we hypothesize as responsible for the relatively large impacts of simulated Seasat data emerges as follows. Given the essentially barotropic nature of the atmosphere over the eastern North Pacific and North Atlantic shown by Blackmon et al., improvements in the surface pres- sure fields can significantly impact tropospheric analyses and forecasts. In terms of geostrophic adjustment theory [e.g., Blumen, 1972], the scale of the wind data assimilated is small compared to the (barotropic) radius of deformation. Therefore it is reasonable to expect wind information to be retained and the mass field to adjust, while temperature data will tend to be radiated away as gravity waves. Further, from a statistical point of view, there is more information in a small orbit segment of wind data than in sounder data of the same size because the correlation scale of winds is smaller. This suggests that wind data can benefit more from the dense coverage that a satellite provides. In addition, the preliminary evaluation of actual SASS data suggests that scatterometer wind errors are a smaller fraction of marine boundary layer wind analysis error than are sounder temperature errors compared to errors in the temperature analysis.

The results of these idealized impact studies, compared with the fact that actual Seasat-1 SASS marine wind data have an accuracy close to nominal specifications suggest that studies involving real SASS global data sets should be undertaken and that serious consideration be given to such data in the design of an optimum global observing system.

Acknowledgments. The authors sincerely appreciate the contributions of Jim Edelmann, Joan Ulrich, Maninn Almeida, and Arkady Plotkin of Sigma Data Services Corporation to this work. The participation of V. Cardone in this study was supported by the Jet Propulsion Laboratory, Califomia Institute of Technology, under contract 95441 with City University of New York, and by NASA Goddard Space Flight Center under contract NAS5-24498 with Oceanweather, Inc. The participation of $M$. Cane was supported in part by NASA grant NGR 22-009-727.

\section{REFERENCES}

Atlas, R., M. Halem, and M. Ghil, The effect of model resolution on satellite sounding data impact, submitted to Mon. Weather Rev., 1981.

Baver, K. G., A comparison of cloud motion winds with coinciding radiosonde winds, Mon. Weather Rev., 104, 922-931, 1976.

Baumhefner, D., and P. Downey, Forecast intercomparisons from 
three numerical weather prediction models, Mon. Weather Rev., 106, 1245-1279, 1976.

Bengtsson, L., and P. Morel, Report on the performance of space observing systems for the First GARP Global Experiment, Rep. 6, GARP Working Group on Numerical Exp., Washington, D. C., 1974.

Blackmon, M. L., R. A. Madden, J. .M. Wallace, and D. S. Gutzler, Geographical variations in the vertical structure of geopotential height fluctuations, J. Atmos. Sci., 36, 2450-2466, 1980.

Blumen, W., Geostrophic adjustment, Rev. Geophys. Space Phys., 10, 485-528, 1972.

Bruce, R. E., L. Duncan, and J. Pierluissi, Experimental study between radiosonde temperatures and satellite derived temperatures, Mon. Weather Rev., 105, 493-496, 1977.

Cardone, V. J., Specification and prediction of the vector wind on the United States continental shelf for application to an oil slick trajectory forecast program, final report, The City College of City University of New York, 1978.

Cardone, V. J., J. D. Young, W. J. Pierson, R. K. Moore, J. A. Greenwood, C. Greenwood, A. K. Fung, R. Salf, H. L. Chan, M. Afarani, and $M$. Komen, The measurement of the winds near the ocean surface with a radiometer-scatterometer on Skylab, A joint meteorological, oceanographic, and sensor evaluation program for Experiment S193 on Skylab, NASA CR-147478, 1976.

Cardone, V. J., A. J. Broccoli, C. V. Greenwood, and J. A. Greenwood, Error characteristics of extratopical storm wmunelds specified from historical data, J. Petrol. Tech., 32, 873-880, 1980.

Cressman, G. P., An operational objective analysis system, Mon. Weather Rev., 85, 367-374, 1959.

Druyan, L., R. Somerville, and W. Quirk, Extended range forecasts with the GISS model of the global atmosphere, Mon. Weather Rev., 103, 779-795, 1975.

Gandin, L. S., Objective analysis of meteorological fields, transl. from Russian by the Israeli Program for Scientific Translations, 1965.

Ghil, M., R. Dilling, and H. Carus, A statistical method for the timecontinuous assimilation of satellite-derived temperatures, paper presented at 5th Conference Probability Statistics, Atmospheric Sci., Am. Meteorol. Soc., Las Vegas, New York, 1977.

Ghil, M., M. Halem, and R. Atlas, Time-continuous assimilation of remote-sounding data and its effect on weather forecasting, Mon. Weather Rev., 107, 140-171, 1979.

Grantham, W. L., E. M. Bracalente, W. L. Jones, and J. W. Johnson, The Seasat-1 satellite scatterometer, IEEE J. Oceanic Eng., $O E-2$, 200-206, 1977.

Halem, M., and G. Russell, A split-grid differencing scheme for the GISS model, Inst. Space Stud. Res. Rev., 194-201, 1973.
Halem, M., M. Ghil, R. Atlas, J. Susskind, and W. J. Quirk, The GISS sounding temperature impact test, NASA Tech. Memo. $78063,1978$.

Jones, W. L., F. J. Wentz, and L. C. Schroeder, Algorithm for inferring wind stress from Seasat-1, J. Spacecraft Rockets, 15, 368-374, 1978.

Jones, W. L., P. G. Black, D. M. Boggs, E. M. Bracaleute, R. A. Brown, G. Dome, J. A. Ernst, I. M. Halberstam, J. E. Overland, S. Peterherych, W. J. Pierson, F. J. Wentz, P. M. Woiceshyn, and M. G. Wurtule, Seasat scatterometer: Results of the Gulf of Alaska Workshop, Science, 204, 1413-1415, 1979.

McPherson, R., Progress, problems and prospects is meteorological data assimilation, Bull. Am. Meteorol. Soc., 56, 1154, 1975.

Nitta, T., G. Gilchrist, A. Lorenc, and D. Williamson, Observing system simulation experiments for the first GARP global experiment, Rep. 10, GARP Working Group on Numerical Experimentation, Location, 1975.

Overland, J. E., and W. H. Gemmill, Marine winds in the New York Bight, Mon. Weather Rev., 105, 1003-1008, 1977.

Phillips, N. A., The impact of synoptic observing and analysis systems on flow pattern forecasts, Bull. Am. Meteorol. Soc., 57, 1225-1240, 1976.

Quirk, W. J., and R. M. Atlas, The effect of increased horizontal resolution on synoptic forecasts with the GISS model of the global atmosphere, paper presented at the Third Conference on Numerical Weather Prediction, American Meteorol. Soc., Omaha, Neb., April 26-28, 1977.

Somerville, R. C. J., P. H. Stone, M. Halem, J. E. Hansen, J. S. Hogan, L. M. Druyan, G. Russell, A. S. Lacis, W. J. Quirk, and J. Tenenbaum, The GISS model of the global atmosphere, J. Atmos. Sci., 31, 84-117, 1974.

Tracton, M. S., A. J. Desmarais, R. D. McPherson, and R. J. Van Haaven, The impact of satellite soundings upon The National Meteorological Center's analysis and forecast system-The Data Systems Test results, Mon. Weather Rev., 108, 543-586, 1980.

Tracton, M. S., R. J. Van Haaven, and R. D. McPherson, On The system dependency of satellite sounding impact-Comments on recent impact test results, Mon. Weather Rev., 109. 197-200, 1981.

Wilcox, R., and F. Sanders, Comparison of layer thickness as observed by Nimbus $E$ microwave spectrometer and by radiosonde, $J$. Appl. Meteorol., 15, 956-961, 1976.

(Received December 1, 1980; revised April 21, 1981; accepted April 27, 1981.) 